\title{
GESTÃO DE MUDANÇAS: JOB ROTATION COMO PRÁTICA PARA TREINAR E DESENVOLVER PESSOAS
}

\author{
CHANGE MANAGEMENT: JOB ROTATION AS A PRACTICE FOR TRAINING AND DEVELOPING PEOPLE
}

Evandro Ferigato ${ }^{1}$, Alessandro Marco Rosini², Marcio Magera Conceição ${ }^{3}$, Ricardo Costa ${ }^{4}$, Ricardo Shitsuka ${ }^{5}$

Submetido em : 25/04/2020

Avaliado em : 05/06/2020

Aprovado em : 09/02/2021

\section{RESUMO}

Este estudo buscou verificar importância da mudança no ambiente organizacional e como ela tem o papel de motivar e treinar a mão de obra com baixo custo através do job rotation. A rotação de trabalho ou job rotation é uma das práticas com baixo custo para começar a mudar esses conceitos de pessoas robóticas, acomodadas e estagnadas em sua vida profissional. Com a inserção dessa prática os resultados surgem a curto e médio prazo, torna os colaboradores mais motivados e treinados na empresa, possibilitando uma visão holística da organização e com foco no seu plano de carreira, em contra partida a organização alavancará seus resultados e conquistará notável melhoria em seus processos e pessoas. Para embasamento do referencial teórico, utilizou-se uma análise sobre o tema

\footnotetext{
1 Mestre em Administração Micro e Pequenas Empresas (UNIFACCAMP) Centro Universitário Campo Limpo Paulista (2015 / 2018); Pós-graduado em Gestão de Pessoas (UNIFACCAMP) Centro Universitário Campo limpo Paulista (2014); Pós-graduado em Logística pela (UNIFACCAMP) Centro Universitário Campo Limpo Paulista (2013); Graduado em Logística (UNIFACCAMP) Centro Universitário Campo Limpo Paulista (2012); Graduado em Publicidade e Propaganda Faculdade Luiz Rosa (2000); Professor Mestre Universitário MBA Pós Graduação e Graduação UNIFACCAMP (Centro Universitário Campo Limpo Paulista) e FFRAMO (Faculdade Francisco Morato) 2013 a Atual; Gerente Comercial Empresa Agropecuária Campo Limpo (Casa do Sitiante) 2010 a 2017; Vendedor Interno Empresa Agropecuária Campo Limpo Paulista (Casa
} do Sitiante) 2005 a 2009. Correio eletrônico: evandroferigato@gmail.com

${ }^{2}$ Pós-Doutor em Administração de Empresas pela FEAUSP. Correio eletrônico: alessandro.rossini@yahoo.com

${ }^{3}$ Pós Doutorando junto a Faculdade Funcional de Ecologia Universidade de Coimbra, Portugal. Projeto em andamento, ano 2018. Pós Doutor junto ao Departamento de Sociologia do Instituto de Filosofia e Ciências Humanas IFCH da Unicamp, SP, sob orientação do Prof. Dr. Ricardo Luiz C. Antunes. Ano 2004 e 2005. Post Doctor in International Relations, do Programa de Estudos de Pós-graduação stricto sensu da Florida Christian University FCU. Memorial de conclusão de curso entregue em novembro de 2013, no Seminário Internacional em Orlando Florida, USA, 2013. Doutor em Ciências Sociais Sociologia Na Pontifícia Universidade Católica de São Paulo-Puc, SP. 2002. Doutor em Administração de Negócios na Florida Cristhian Universit FCU USA, 2010. Mestre em Ciências Sociais Área de Concentração Sociologia, pela Puc SP. 2001. Mestre em Administração de Empresas pela Universidade de Guarulhos -SP, 1999. MBA de Gestão de Marketing na ESAMC Sorocaba, SP, 2007 Graduado: Bacharel em Ciências Econômicas - Pontifícia Universidade Católica de Campinas SP. Ano 1993. Jornalista MTB 556.03.81VSP. Correio eletrônico: magera1963@gmail.com

${ }^{4}$ Pós-Doutorado em Comunicação pela Universidade Estadual de Campinas - UNICAMP, Doutor em Ciências Sociais pela Pontifícia Universidade Católica de São Paulo - PUC/SP, Mestre em Comunicação Social pela Universidade Metodista de São Paulo - UMESP. Possui graduação em Comunicação Social. Especialista em Gestão de Ecossistema Digital. Colaborador no INEP atuando como avaliador de cursos presenciais e EaD. Possui experiência na área de Gestão Educacional e na Gestão corporativa atuando principalmente nos seguintes temas: Marketing,, Retenção, Captação, Comunicação e Educação a Distância. Pesquisador da Universidade Federal de Minas Gerais. Professor do Programa de Mestrado em Análise Geoambiental.

${ }^{5}$ Doutor em Ensino de Ciências na Universidade Cruzeiro do Sul. Mestre em Engenharia pela EPUSP. Pós-graduação em Tecnologia, Formação de Professores e Sociedade na UNIFEI. Pós-graduação em Tecnologias Educacionais pela FAAP. Pós-graduação em Design Instrucional para EAD pela UNIFEI. Graduação em Pedagogia. Graduação em Odontologia. Graduação em Licenciatura em Computação . Graduação em Engenharia. Correio eletrônico: ricardoshitsuka@unifei.edu.br 
abordado nas empresas e percebeu-se que desde o início que as mudanças permearam as constantes mudanças que ocorrem nas organizações, e com base nesses fatos a pesquisa se desenvolveu com a abordagem da gestão de mudanças e a inserção do job rotation no âmbito organizacional, para isso o conteúdo foi complementado e adequado mediante pesquisas bibliográficas em livros e artigos científicos para ter como resultado um trabalho didático. Foi possível obter um melhor entendimento sobre a influência da motivação nas pessoas e como a falta dela pode afetar as organizações influenciando a rotatividade. Quando aplicado de forma correta, o job rotation, cada colaborador poderá identificar uma nova área de interesse, aumentar sua satisfação na organização, ficar mais motivado e comprometido com seu trabalho e elevará seu desempenho. O planejamento, controle e acompanhamento podem dessa forma trazer resultados duplos tanto para a organização quanto para o colaborador, a organização vai treinar e desenvolver seu capital humano, tornando-o motivado e terá seus resultados revertidos em produtividade e em um clima organizacional agradável, sem mencionar a oportunidade de enxergar um novo talento interno do colaborador nos setores que este percorrer na empresa durante o período do job rotation.

PALAVRAS-CHAVE: : Estratégia. Metodologia. Benefícios. Competitivo. Objetivo.

\section{ABSTRACT}

This study sought to verify the different tools available to the manager for people management, including practical cases. The aim is to demonstrate how strategic planning can change the entire productive capacity of a company and its results, reaching goals and positioning itself in the market. People management is essential when conducting a project, as it works to meet deadlines while maintaining financial viability. However, to achieve this objective, the mentioned tool needs strategic planning. But what will strategic planning add to people management? Will the company have any benefit from using strategic planning? The objective is to analyze and show the importance of strategic planning as a tool in project management and its influence on the economic impact within the organization. To support the theoretical framework, we used the starting point of bibliographical research of books, monographs, articles and documents about the proposed theme, conducting a descriptive and exploratory study. According to Severino (2010), exploratory research aims to collect and seek information about a particular subject or object of study in order to map the conditions of manifestation of this object. It has been found that people management proves to be the technical mechanism capable of directing these policies and strategies to achieve business objectives, with several advantages such as budget forecasting and the ability to be applicable to enterprises of various types. complexities. Several tools and information systems are made available to the manager to measure and apply actions aimed at guiding its strategic management, anticipating possible threats and opportunities, targeting its actions adapting to the corporate market in which it operates. Faced with the globalization scenario and constant technological advancement of the market, the business environment becomes increasingly competitive and demanding. It is relevant that companies seek strategic planning in their people management. It is also necessary for companies to be increasingly flexible and adaptable to the corporate market. People management is essential as the technical mechanism for directing these policies and strategies, increasing profits and efficiency, reducing the possibility of errors and delays. Planning, control and follow up can thus bring double results to both the organization and the employee, the organization will train and develop its human capital, making it motivated and will have its results reversed in productivity and in an organizational climate. pleasant, not to mention the opportunity to see a new internal talent of the employee in the sectors that he travels in the company during the period of job rotation.

KEYWORDS: Strategy. Methodology. Benefits. Competitive. Objective. 


\section{INTRODUÇÃO}

Atualmente nas organizações nos deparamos com a seguinte situação: colaboradores acomodados e robóticos no trabalho que desempenham e na maioria dos casos desmotivados e sem perspectivas de crescimento profissional. A gestão contemporânea enxerga estes como pessoas e não como números e isso possibilitam a reversão dessa situação e a aplicação de mudanças para treiná-los, desenvolvê-los e motivá-los. A mudança é um fator que ocorre o tempo todo, está presente na vida das organizações e das pessoas, entretanto no ambiente de trabalho esta pode ocorrer de maneira rotineira e não como um fator que leve as pessoas a novos desafios, o objetivo principal objetivo desse estudo é falar da importância da mudança no ambiente organizacional e como ela tem o papel de motivar e treinar a mão de obra com baixo custo através do job rotation.

Esse estudo foi realizado após uma análise no âmbito organizacional e a identificação da desmotivação por conta da rotina maçante de trabalho, as pessoas se sentem como robôs quando permanecem na mesma função por muito tempo e através de pesquisas bibliográficas em livros, revistas, artigos acadêmicos e internet a solução encontrada para mudar essa situação é inserir nessas organizações o job rotation que é uma prática utilizada para treinar, desenvolver os colaboradores e expandir o conhecimento e aprendizado destes dentro da empresa.

A aplicação dessa ferramenta de forma coesa e planejada trará resultados imediatos para os colaboradores através de novos conhecimentos e saída da zona de conforto em contrapartida para a empresa a médio e longo prazo terá uma equipe treinada e qualificada para assumir novos desafios e metas organizacionais, segundo Jucius (1983), a administração de pessoal é o campo da administração que utiliza as funções da administração que são: planejar, organiza, dirigir e controlar as funções de procura, desenvolvimento, manutenção e utilização da força de trabalho visando atingir os objetivos da empresa economicamente e eficazmente conciliando-os com as finalidades de todos os níveis de pessoal.

O job rotation é uma forma de motivar o colaborador e prospectar um plano de carreira dentro da organização, pois o colaborador quando se encontra muito tempo na mesma função sua rotina de trabalho torna-se cada vez mais exaustiva e não possibilita o aprendizado em outras funções, com a inserção dessa ferramenta podemos rever- ter essa situação com baixo custo e desenvolver e treinar a mão de obra da empresa para novos objetivos e metas.

\section{REFERENCIAL TEÓRICO}

\section{MUDANÇAS}

Segundo Chiavenato (2004/2016), a mudança está em toda parte, nas organizações, nas pessoas, nos clientes, nos produtos e serviços, na tecnologia, no tempo e no clima, a mudança representa a principal característica dos tempos modernos. O autor ainda descreve a mudança como uma passagem de um estado para outro diferente, é a transição de uma situação para outra.

Observamos que tanto na vida pessoal como nas organizações e nos fatores climáticos a mudança sempre está ocorrendo, em algumas situações são controláveis após a interferência do ser humano, porém em alguns casos são situações incontroláveis, como por exemplo, as questões climáticas. Nas organizações não é diferente, existem mudanças que são controláveis e incontroláveis. Silva, Araujo e Vaz (2009), entendem a mudança organizacional como resultado de fatores internos e externos que afetam diretamente o funcionamento das organizações. Esses autores afirmam que entre as fontes externas estão à ocorrência de eventos ambientais, como as oscilações do mercado e da concorrência, as reformulaçóes políticas governamentais ou as alterações em um grande grupo de empresas. No nível interno, as mudanças ocorrem devido à ação estratégica da alta administração, que visa à reformulação de novos objetivos a serem alcançados pelas empresas, à implantação de sistemas de planejamento e controle, além das situações relacionadas aos processos interativos dos integrantes da organização. Além disso, a mudança também pode ocorrer, a partir de ações isoladas exercidas pela alta cúpula da organização.

Para Oliveira, Duarte e Montevechi (2002) a mudança é um processo complexo, ou seja, pode ser planejada ou simplesmente acontecer. Os autores afirmam que as mudanças nas estruturas das organizações podem ser interpretadas de duas maneiras: a mudança não planejada e a mudança planejada ou estratégica. No processo não planejado, a organização procura manter-se no curso, ou seja, solucionando problemas à medida que aparecem. Já a mudança planejada ou estratégica, procura atingir um objetivo estabelecido, incorporando esse objetivo aos membros da organização. 
As mudanças externas ou não planejadas como os autores mencionaram acima, exige uma atenção maior, pois estas não podem ser controladas pelos gestores é preciso achar caminhos e estabelecer diretrizes para se adaptar a essas transformações, pois são incontroláveis, entretanto as mudanças internas ou planejadas estrategicamente caso feitas da maneira correta é possível alcançar o objetivo proposto.

A mudança é cada vez mais uma constante em nossas vidas, observamos isso nas questões ambientais sociais e econômicas e na maioria das vezes são desencadeados por nós seres humanos, pois temos o poder de influenciar e ser influenciados pelo meio que vivemos, nas organizações não é diferente as mudanças estão ocorrendo o tempo todo, porém não é um fator tão simples quanto parece, ela pode ser interna ou externa, planejada ou não, Chiavenato (2014/2016) ainda afirma que muitos programas de mudança organizacional simplesmente não funcionam porque se limitam a mudanças no trabalho, e não na atitude e no comportamento das pessoas. O primeiro passo está em mudar o comportamento individual para posteriormente ter condições de mudar o organizacional. Para tanto, é necessário que as pessoas visualizem claramente o que deve ser mudado e concordem com isso para depois alcançar a mudança. Daí pra frente pode-se então mudar a estrutura organizacional que envolve as pessoas.

Na gestão contemporânea a mudança está sempre ocorrendo e como mencionada acima pelo autor o foco da mudança deve partir primeiro das pessoas, deve-se valorizar o capital humano para depois implantar as mudanças estruturais na organização.

\section{CULTURA ORGANIZACIONAL}

A cultura organizacional é o modo de vida da organização, ou seja, a forma como conduz seu negócio em todos seus aspectos, equivale ao modo como trata seus clientes e colaboradores, seu modo de gestão dentre outros inúmeros fatores que distinguem uma organização das demais.

Segundo Chiavenato (2014/2016) a Cultura Organizacional ou cultura corporativa é o conjunto de hábitos e crenças estabelecidos por normas, valores, atitudes e expectativas que é compartilhado por todos os membros de uma organização. A cultura nada mais é do que o DNA que representa a identidade da empresa, por esse fato muitas organizações são conhecidas por algumas peculiaridades, podendo ser considerada uma empresa com cultura forte ou não, o ideal é sempre ser forte, pois significa que todos os membros daquela organização compartilham seus valores e isso reflete no seu comportamento e em seu trabalho. $O$ autor ainda afirma que a cultura exprime a identidade da Organização, é construída ao longo do tempo e passa a impregnar todas as práticas, um complexo de representações mentais e um sistema coerente de significados que une todos os membros em torno do mesmos objetivos e dos mesmos modos de agir. Serve de elo entre o presente e o passado e contribui para a permanência e coesão da organização. (CHIAVENATO, 2014/2016)

Segundo Freitas (1991), a cultura organizacional é como um poderoso mecanismo que visa a conformar condutas, homogeneizar maneiras de pensar e viver na organização, trazendo para dentro de si uma imagem positiva da mesma, onde todos são iguais. Freitas (1991) utiliza o conceito de Schein (1984) para definir cultura organizacional, onde esta significa princípios que grupos organizacionais têm inventado ou desenvolvido no processo de aprendizagem para lidar com os problemas de adaptação externa e integração interna. A partir da citação dos autores observamos as duas vertentes da cultura organizacional, por um lado - internamente - mostra como os funcionários devem agir, se portar e fazer suas tarefas, por outro lado - externamente- ela é influenciada pelo meio em que está situada tendo que se adaptar ao mercado para produzir produtos ou serviços perante as diretrizes legais, sociais e culturais do local onde ela se encontra.

A cultura organizacional pode ser percebida por todos, porém alguns aspectos são menos visíveis, podemos fazer uma analogia de cultura organizacional com um iceberg, apenas uma parte fica visível e a outra fica submersa na água fora nosso campo de visão, assim é a cultura, segundo Chiavenatto a Cultura organizacional mostra aspectos formais e facilmente perceptíveis como suas políticas, métodos e procedimentos, objetivos, estrutura organizacional e a tecnologia dotada. Podemos associar esses aspectos a parte visível do iceberg, o autor ainda complementa: Contudo ela oculta alguns aspectos informais, como percepções, sentimentos, atitudes, valores, interações informais, normas grupais, etc. Esses aspectos mencionados pelo autor são os mais difíceis de serem observados, interpretados e compreendidos, assim como difíceis de mudar ou sofrer qualquer transformação, sendo a parte inferior do iceberg. Compreendemos melhor a analogia na Figura abaixo: 
FIGURA 1 - O ICEBERG DA CULTURA ORGANIZACIONAL

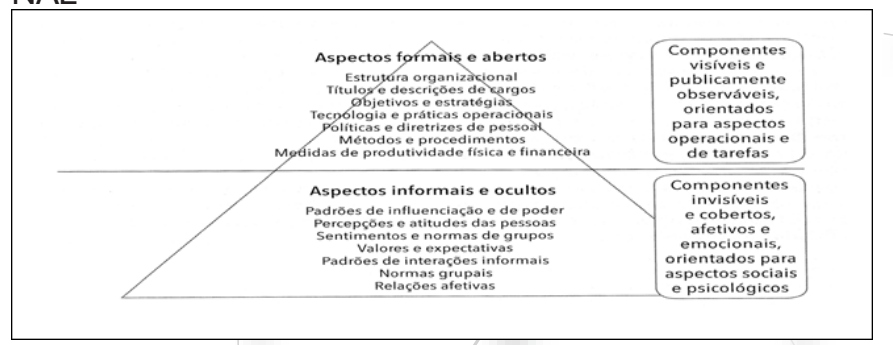

Fonte: Chiavenato, 1999, p.40

A cultura pode levar uma empresa tanto ao sucesso como ao fracasso, se ela for flexível pode gerar grandes avanços, porém se ela for rígida e autoritária a tendência é não alcançar o desenvolvimento esperado. Existem culturas adaptativas e conservadoras, as culturas conservadoras permanecem com sua cultura intacta desde sua entrada no mercado, não sofrem nenhuma alteração nos seus valores, crenças, hábitos, regras, costumes, etc. Não mudam ao longo do tempo e acabam ficando paralisadas, já as culturas adaptativas são mais flexíveis e em constante revisão caracterizando-as pela criatividade, inovação e mudança.

\section{CONCEITO JOB ROTATION}

As Palavras do inglês "Job" e "Rotation" se traduzidas para o português "Rotação de trabalho" é um termo utilizado na gestão contemporânea, antigamente e ainda hoje em algumas organizações os colaboradores passam por um processo parecido em sua integração, onde estes visitam vários setores a fim de conhecer mais a empresa e seu processo para quando voltar a sua posição possuir um breve conhecimento do negócio e dar andamento na sua função com mais familiaridade com o local de trabaIho. Atualmente essa prática é utilizada para treinamento e desenvolvimento de carreira dentro das organizações. Segundo Chiavenato (2014/2016) a rotação de cargos significa a movimentação das pessoas em várias posições na organização no esforço de expandir habilidades, conhecimentos e capacidades. $\mathrm{O}$ autor ainda afirma que a rotação de cargos representa um excelente método para ampliar a exposição das pessoas às operações da organização e transformar especialistas em generalistas, permite o aumento das experiências individuais e estimula o desenvolvimento das novas ideias ao mesmo tempo que proporciona oportunidades para uma avaliação de desempenho mais ampla e confortável do funcionário. (CHIAVENATO, 2014/2016).

A rotação no trabalho é uma prática que implica a transferência de um departamento para outro, de modo a aumentar as credenciais do trabalhador em todos os aspetos. É planeada de acordo com a prática do trabalho e promove a aquisição de novas competências e o aumento da produtividade (Jaturanonda et al., 2006).

De acordo com Bennett (2003), a rotação de empregos é uma substituição planejada de funcionários entre vários empregos dentro de um período de tempo, a fim de aprimorar as habilidades e a independência do trabalho, resultando em aumento da motivaçắo, desempenho e produtividade do trabalho. Da mesma forma, Gomez, Lorente e Cabrera (2004) definem a rotação de trabalho como o trabalho em diferentes cargos ou situações em períodos de tempo classificados em uma variedade de conhecimentos, habilidades e capacidades individuais dos funcionários. Jaturanonda, Nanthavanij e Chongphaisal (2006) descobriram que as organizações dos setores público e privado consideravam o 'conhecimento, habilidades e habilidades' combinados como o critério de decisão predominante sobre quem girar, independentemente do objetivo da rotação de tarefas. A rotação de empregos ou o treinamento cruzado (Ho, Chang, Shih \& Liang, 2009) visa ampliar o conhecimento, as habilidades e a experiência, deslocando pessoas de emprego em emprego ou departamento para departamento (Delpasand, Raiisi, Begdely \& Shahabi, 2010; Lindbeck \& Snower, 2000; Olorunsula, 2000). Pode ser um método ineficiente e frustrante de adquirir conhecimentos e habilidades adicionais, a menos que seja cuidadosamente planejado e controlado. A rotação de empregos é uma mudança sistemática de funcionários, transferindo-os entre várias áreas de responsabilidade, na tentativa de melhorar a experiência dos funcionários no trabalho (Dessler \& Varkkey, 2009; Malinski, 2002; Zin, Mohd Shamsudin \& Subramaniam, 2013). A esse respeito, Dubois (2000), Williams, Cantillon e Cochrane (2000) e Ebadan e Winstanley (1997) concluíram que, se os funcionários valorizam a segurança no emprego, o aumento de movimentos laterais será imprescindível para permitir a renovação e o crescimento organizacional no futuro. A rotação é cuidadosamente planejada e formalmente desenvolvida, possui numerosos benefícios percebidos e é particularmente útil na indústria de transformação (Cheraskin \& Campion, 1996). 


\section{SATISFAÇÃO NO TRABALHO}

Graça (1999), define a satisfação no trabalho como uma atitude, uma emoção ou um sentimento, que resulta da avaliação que o profissional faz das várias dimensões da satisfação, consoante a sua expectativa, em comparação com outros trabalhadores e tendo em conta os investimentos que realizou. Resulta da obtenção de determinados resultados ou recompensas. Manifesta-se na saúde, qualidade de vida e nos comportamentos dos trabalhadores, o que se irá refletir a nível particular e a nível coletivo através da organização. De acordo com Murrells, Clinton, e Robinson (2005) a satisfação e as suas dimensões são partes integrantes dos cuidados, particularmente nos resultados de saúde, o que constitui um indicador de qualidade dos cuidados de saúde.

\section{VANTAGENS DO JOB ROTATION PARA A EMPRESA}

Muitas empresas optam por criar uma política de rotação de empregos como um benefício para os colaboradores. Mas os mesmos não são os únicos que se beneficiam do programa.

Benefícios dos programas de rotação de empregos para colaboradores e empregadores.

\section{Elimina o tédio}

Apenas $32 \%$ dos colaboradores estão realmente envolvidos em seus trabalhos. Isso significa que $68 \%$ dos que estão fazendo o mínimo necessário, conectando seus computadores ou conversando de maneira robótica com os clientes. Os colaboradores desmotivados podem ser atraídos pelas promessas de um trabalho melhor e mais desafiador.

Dar novas responsabilidades aos colaboradores não resolverá todos os problemas. Mas isso pode ajudá-los a se engajar e evitar o tédio. Na maioria das vezes, os colaboradores se desmotivam em seus empregos, é algo gradual. Ao misturar responsabilidades, você pode ajudar a quebrar a monotonia do dia a dia de um funcionário.

\section{Incentiva o desenvolvimento}

Ter uma estratégia de rotação de tarefas ajuda os colaboradores a desenvolver suas habilidades. Ao aprender mais habilidades, se sentirão mais valiosos para as or- ganizações.

Os colaboradores que trabalham em uma empresa que incentiva seu desenvolvimento podem não sentir a necessidade de mudar de emprego. Em vez de deixar a empresa para um novo emprego que ajude o mesmo a se desenvolver, eles podem alternar os empregos.

\section{Dá aos colaboradores uma pausa nas tarefas árduas no trabalho}

Muitos setores que exigem mão de obra pesada usam estratégias de rotação de tarefas. Colaboradores sobrecarregados que trabalham constantemente com mão de obra beneficiam-se de uma pausa. Ao alternar seus trabalhos, as empresas ajudam a compensar o risco de fadiga. Um exemplo, um colaborador do armazém que levanta pacotes pesados para entregas alternar para um trabalho que lida com a papelada para remessa.

\section{Ajuda a identificar onde os colaboradores trabalham melhor}

Uma estratégia de rotação de tarefas pode apontar os pontos fortes e fracos de um colaborador. A empresa pode achar que um colaborador pode lidar melhor com um trabalho diferente na sua empresa. Para os negócios mais eficazes, se faz necessário ter todos os colaboradores nas posições certas.

\section{Oferece um plano de backup se um funcionário dei-} xar

Embora a rotatividade de funcionários possa ser cara, ela não precisa ser devastadora. Por ter um plano de rotação de tarefas, as organizações devem possuir vários colaboradores que sabem como executar cada tarefa.

Se um colaborador for embora, não será necessário contratar sem antes verificar o quadro de funcionário que as empresas possuem e identificar os colaboradores capazes de cobrir as tarefas do colaborador que se desligou. Se precisar contratar um substituto, toda empresa deve reservar um tempo para encontrar o que se adapta melhor na função e fazer o ajuste certo.

\section{DESVANTAGENS DO JOB ROTATION}

Antes de implementar um programa de rotação 
de tarefas, toda organização deve considerar as seguintes desvantagens.

\section{Pode ser caro e demorado}

Quando se desloca um colaborador para uma nova posição, há uma curva de aprendizado. Os mesmos podem precisar de treinamento para realizar seu novo trabalho. $\mathrm{O}$ custo do treinamento de colaboradores pode ser oneroso e levar horas.

\section{Poderia acabar com colaboradores descontentes}

Alguns colaboradores podem não querer alternar trabalhos. Um funcionário confortável e bem-sucedido em sua posição atual pode se preocupar com a possibilidade de outro colaborador atrapalhar seu processo.

Algumas empresas podem ter alguns colaboradores que se destacam em seu trabalho, mas não estão dispostos a aprender coisas novas. E poderá ocorrer de alguns colaboradores estressados com a perspectiva de mudar de função ou tarefa.

\section{Não vai resolver todos os seus problemas}

Não é garantido que os programas de rotação de tarefas aumentem o envolvimento dos colaboradores; Alguns colaboradores podem não estar envolvidos com as organizações, pode ser por causa de outros fatores.

A rotação do trabalho de um colaborador não resolverá problemas como falta de reforço positivo e se desconectará da cultura da empresa. Não use um programa de rotação de tarefas com o único objetivo de fazer os mesmos felizes antes de começar a resolver os problemas primeiro.

\section{Pode não ser viável para algumas empresas.}

Para alguns setores e posições, a rotação de tarefas não é realista. Isto é especialmente verdade em cargos altamente qualificados, onde os colaboradores precisam de anos de treinamento para realizar seu trabalho.

\section{As empresas podem sofrer}

Uma das desvantagens mais devastadoras da rotação de empregos é que as empresas podem sofrer um impacto. Como os colaboradores estão aprendendo novas habilidades, pode haver alguns erros. Os clientes podem ficar frustrados com colaboradores confusos que cometem erros. Se as operações não derem certo, os resultados poderão ser comprometidos.

\section{MÉTODO DE PESQUISA \\ Problema da Pesquisa}

Essa pesquisa foi elaborada após uma análise sobre o tema abordado nas empresas e percebeu-se que desde o início que as mudanças permearam as constantes mudanças que ocorrem nas organizações, e com base nesses fatos a pesquisa se desenvolveu com a abordagem da gestão de mudanças e a inserção do job rotation no âmbito organizacional, para isso o conteúdo foi complementado e adequado mediante pesquisas bibliográficas em livros e artigos científicos para ter como resultado um trabalho didático.

\section{Justificativa}

Para constituição do tema de pesquisa alguns fatores são necessários: importância, viabilidade e originalidade (Castro, 1977).

No que se refere à importância de um tema, Castro (1977, P. 56) destaca:

Dizemos que um tema é importante quando esta de alguma forma ligado à uma questão crucial que polariza ou afeta um segmento substancial da sociedade. Um tema pode também ser importante se esta ligado à uma questão teórica que merece atenção continua na literatura especializada [...].

Macêdo (2007) afirma que a empresa que deseja trabalhar o conhecimento e o desenvolvimento deve saber ensinar, para construir uma boa aprendizagem, a pensar e escutar corretamente. Em outras palavras, além de muito bem planejado, o treinamento deve ser aplicado de maneira correta pela empresa, caso contrário, os colaboradores treinados não irão aprender, seu desenvolvimento técnico e raciocínio não terão aumento significativo, e o conteúdo não terá relevância, logo, se torna um gasto, melhor colocado, um prejuízo.

O colaborador se sente mais valorizado quando 
percebe o quanto está sendo investido em si. Quando a empresa acredita nele, ele também acredita em si, isso faz uma troca equivalente de sentimentos bons, e este acaba sendo um ponto crítico de autoestima empresarial, e todos aqueles que tiverem contato com este colaborador estarão sendo também influenciados pelas ideias deste colaborador, que compra a ideia e defende a cultura da empresa, refletindo em seu comportamento a visão e política da empresa, difundindo nos demais a esperança e a busca em se tornar um capital de investimento intelectual da organização, transmitindo seu conhecimento adquirido, as técnicas desenvolvidas e satisfação pessoal para com a empresa, gerando um clima organizacional bom e competitivo.

\section{ANÁLISES QUADRO ATUAL}

A busca por uma oportunidade no mercado de trabaIho pode ocorrer por diversos motivos, seja necessidade, crescimento profissional, inserção no mercado de trabalho e em muitos casos desmotivação no atual emprego, é um grande desafio manter as pessoas centradas, motivadas e com foco nos resultados, ainda mais quando estas não estão felizes com o ambiente corporativo.

Muitas pessoas por executarem trabalhos repetitivos ou estarem na mesma função a muito tempo ficam entediadas e a tendência é a insatisfação e desmotivação no trabalho, arrumar estratégias para combater esse problema é a dificuldade de muitas organizações, pois as alternativas mais fáceis geram altos custos.

\section{CRESCIMENTO PROFISSIONAL}

Os colaboradores em sua maioria traçam sua trajetória ao entrar em uma organização e é preciso que a organização também trabalhe com base nos interesses profissionais de seus colaboradores, muitas organizações investem em cursos técnicos e superiores, ajudam com uma percentagem da mensalidade, investem em treinamentos etc., com intuito de motivá-los e ajudá-los a alcançar posições que almejam dentro da organização.

Muitos esperam e desejam que seja da forma mencionada acima porém para isso as organizações precisam dispor de recursos financeiros ou fazerem parcerias com instituições de ensino, mas sempre é possível, pois é preciso fazer um planejamento de forma bem estruturada $e$ dependendo do número de colaboradores pode gerar uma despesa extra não planejada.

Pensar em formas simples e com baixo custo para treinar e desenvolver pessoas não é uma tarefa fácil, porém também não é impossível, às vezes pequenas ações geram grandes resultados.

\section{INSERÇÃO DO JOB ROTATION}

Com base nas oportunidades encontradas na atual gestão de pessoas, uma das práticas encontradas para iniciar um processo de mudança onde as pessoas sintam-se valorizadas e treinadas e que não exija da organização altos custos é o Job rotation ou Rotação do Trabalho. Veridiane Oliveira afirma que segundo Jurandir Peinado e Alexandre Reis Graeml, o objetivo do método de rotação do trabalho é a redução da monotonia e o tédio no trabalho causado principalmente pelo excesso de especialização do trabalhador.

\section{ETAPAS \\ - CONSCIENTIZAÇÃO}

O primeiro passo é informar os colaboradores sobre a inserção da prática em sua rotina de trabalho, muitos não estarão dispostos a participar do experimento que a organização está propondo, justamente por estarem acomodados na sua zona de conforto, a conscientização dos membros da empresa sobre os benefícios, sobre o funcionamento, e quais os objetivos da organização com a implantação da rotação do trabalho, pode gerar curiosidade e a tomada de decisão sobre o novo desafio.

\section{- CULTURA DA EMPRESA}

A cultura da empresa pode ser uma barreira ou pode ser uma forma de alavancar esse processo, culturas conservadoras não permitem a inserção de novas práticas, são altamente inflexíveis e autoritárias, por outro lado temos as culturas adaptativas que tendem a serem mais flexíveis e apostam em novos conceitos e métodos para tornar seu time mais coeso e eficaz. A gestão contemporânea tem o foco nas pessoas e práticas que visam o melhor entrosamento e desenvolvimento que resulte em ganhos para empresa que são sempre bem-vindas. 


\section{- PLANEJAMENTO}

Um dos pontos mais importantes quando uma organização deseja fazer uma mudança é o planejamento, é fundamental planejar a implantação da rotação do trabalho, onde será feito, quando será feito, como será feito etc., pois se trata de uma prática nova na organização e o novo pode assustar de início e se não for bem estruturado e alinhado com a missão e os valores da empresa pode gerar resultados reversos, sendo assim é preciso antes de tudo esboçar e desenvolver um planejamento que ajude e garanta a eficácia nos resultados da inserção de uma nova prática no ambiente de trabalho.

\section{- APLICAÇÃo}

Pode ser bem aceita ou não, esta depende dos outros quesitos mencionados acima, se todas as etapas estiverem bem aplicadas e estruturadas o job rotation será uma prática de grande valia para a empresa e para o plano de carreira dos colaboradores que participarem da rotação de trabalho.

\section{- MENTORES}

Para acompanhar o processo de um colaborador em uma função que até o momento é desconhecida para o mesmo, é importante que este tenha um mentor, ou como muitos preferem chamar um padrinho ou madrinha, que o ajudará na apresentação prévia do trabalho, irá esclarecer as possíveis dúvidas e deixar bem claro as intenções da empresa como já foi dito de forma geral. É ideal que o gestor peça relatórios do mentor e do colaborador a fim de acompanhar os resultados, já durante a rotação de cargos.

\section{- MÉTOdo DE AVALIAÇÃo}

Outro ponto fundamental é a definição dos métodos de avaliação sem os quais não teria sentido o sistema. O método que sugerimos é o sistema de Avaliação de Desempenho através de questionários, onde antes e depois da implantação o colaborador é avaliado pelo gestor e o por ele mesmo, a fim de perceber a evolução e os resultados obtidos. Sem contar os relatórios e dos mentores que estão dia-a-dia com ele.

Coordenando o relacionamento de diferentes colaboradores e departamentos para evitar brigas internas entre facções, as empresas devem evitar grupos de departamento ou executivo, as empresas devem defender ativamente a cultura corporativa de integridade. Dentro da empresa, construir a atmosfera de entendimento mútuo, respeitando e ajudando entre os membros líderes, colegas e departamentos. Os colaboradores podem disputar por causa de problemas no trabalho, mas não podem fazer política, intrigar, estruturar e se amontoar por problemas pessoais ou por suas próprias vantagens; caso contrário, os colaboradores se concentrarão nos relacionamentos interpessoais da empresa, mas ignorarão seu trabalho. Em longo prazo, fará com que os mesmos trabalhem quedas de eficiência, para piorar a situação, acabarão por liderar a rotatividade de colaboradores. Para lidar adequadamente com os grupos informais internos e guiar estes grupos, as organizações devem dedicar todo o seu tempo à influência positiva dos grupos informais, enfraquecendo seus efeitos negativos. Lidar com os relacionamentos dentro de uma empresa reduz fatores de rotatividade desnecessários.

\section{- FEEDBACK}

Um feedback com o RH para finalizar o processo e mostrar a identificação dos resultados podendo afirmar se ele é ou não um candidato a mudar de função ou traçar um plano de carreira é o indicado e também a avaliação de possíveis falhas no sistema para constantes melhorias. Estas considerações devem ser levadas em conta para que a companhia tenha eficiência e eficácia nas aplicações de rotação do trabalho, sem as quais não é possível conseguir os resultados do método, tornando-o dispensável.

\section{- TURNOVER}

Rotatividade de funcionários é um termo que se aplica aos funcionários que saem da empresa devido à demissão, tendo um emprego melhor ou porque sentiam que não havia espaço para crescimento, ou pior, que estavam lidando com um ambiente de trabalho hostil ou discriminatório. Uma taxa de rotatividade diz mais sobre uma empresa do que sobre um funcionário. Uma alta taxa de rotatividade normalmente significa que as condições de trabalho não são ideais, os salários estão abaixo da média do mercado ou os funcionários não são bem treinados. Simultaneamente, uma baixa taxa de rotatividade indica um ambiente de trabalho em que os funcionários se sentem apreciados, trabalham em equipe, têm espaço para subir a 
escada corporativa e estão satisfeitos com seus trabalhos.

\section{RESULTADOS}

A inserção do Job Rotation em uma organização resulta obtenção de novos conhecimentos por parte dos colaboradores em diferentes setores da empresa e o acúmulo de novas experiências, sem sair da companhia em que trabalha, pode parecer uma prática simples, e realmente é, porém exige planejamento, controle e acompanhamento que constatem dessa forma poder trazer resultados duplos tanto para a organização quanto para o colaborador. A organização vai treinar e desenvolver seu capital humano, tornando-o motivado e terá seus resultados revertidos em produtividade e em um clima organizacional agradável, sem mencionar a oportunidade de enxergar um novo talento interno, do colaborador nos setores, que este percorrer na empresa, durante o período do job rotation. O colaborador por sua vez poderá identificar uma nova área de interesse, aumentar sua satisfação na organização, ficar mais motivado e comprometido com seu trabalho e elevará seu desempenho.

\section{CONCLUSÃO}

A gestão de pessoas já sofreu muitas mudanças até chegar à fase que se encontra atualmente, porém mesmo com tanta evolução percebemos e encontramos muitas oportunidades de melhorar, desenvolver e treinar o capital humano, e a tendência é que a mudança sempre ocorra nesse meio para trazer mais benefícios e não cair na rotina, práticas e diretrizes que norteiam a gestão contemporânea.

Hoje o foco de uma organização não basta ser apenas em produtos e serviços, a moderna gestão deve ser voltada para pessoas e a valorização, desenvolvimento e treinamento das mesmas, assim os processos fluírão de forma continua e com qualidade, revertendo o investimento em sua produtividade e em um ambiente de trabalho saudável onde os resultados surgirão com excelência e de forma natural.

A rotação de trabalho é fundamentada com base na missão, na visão e nos valores da empresa, onde a cultura tem um importante papel de concretizar a inserção dessa prática a fim de desenvolver sua mão de obra de forma criativa e inovadora, consciente da importância de profissionais capacitados para o sucesso da organização por sua capacidade de reter talentos e valorizá-los, diferenciando-se dessa forma de eventuais concorrentes e ganhando vantagens no mercado de trabalho, sem contar os ganhos referentes a produtos e serviços prestados.

\section{REFERÊNCIAS}

BENNETT, B. Jobrotation: Its role in promoting learning in organizations. Developmentand Learningin Organizations,v. 17, n. 4, p. 7-9. 2003.

BOOG, Gustavo G. (coord). Manual de Treinamento e Desenvolvimento ABTD. São Paulo: MAKRON Books, 1994.

CANABRAVA, Tomasina; VIEIRA, Onízia de Fátima Assunção. Treinamento e desenvolvimento para empresas que aprendem. Brasília: Editora Senac-DF, 2006.

CARVALHO, Antonio Vieira de; NASCIMENTO, Luiz Paulo do. Administração de Recursos Humanos, $v 1$. São Paulo: Pioneira Thomson Learning, 2004.

CASTRO, Claudio de Moura. A prática da pesquisa. Sao Paulo: McGraw-Hill do Brasil, 1977.

Cheraskin, L.; Campion, M.A. Study clarifies job rotation benefits. Personnel Journal, v. 75, n. 11, p. 31-38. 1996.

CHIAVENATO, Idalberto. Gestão de Pessoas. O novo papel dos recursos humanos nas organizações. Editora Manole 2004, 4. ed. 2016.

DELPASAND, M.; RAIISI, P.; BEGDELY,F.; SHAHA$\mathrm{Bi}, \mathrm{M}$. The impact of job rotation on nurse burn out of Kash an i hospitalinTehran, Iran. Occupational Health Journal, v. 7, n. 4, p. 121-188. 2010.

DESSLER, G.; VARKKEY, B. Training and development. Human Resource Management. New Delhi: Dorling Kindersley (India) Pvt. Ltd. 2009.

DUBOIS, D. D. The seven stages of one's career. Training and Development, ASRD Inc. Alexandria VA, v. 54 , n. 12, p. 45-50. 2000. 
EBADAN, G.; WINSTANLEy, D. Downsizing, delayering and career. The survivor's perspective. Human Resource Management Journal, v. 7, n. 1, p. 79-91. 1997.

FREITAS, Maria Ester de. Cultura organizacional: formação, tipologias e impacto. São Paulo: Makron, McGraw-Hill, 1991.

GESTÃO DA MUDANÇA ORGANIZACIONAL. Disponível em: http://bibliotecadigital.fgv.br/dspace/ bitstream/handle/10438/11826/Gest\%C3\%A3o\%20 da\%20Mudan\%C3\%A7a-Uma\%20Revis\%C3\%A3०\%20 Te\%C3\%B3rica.pdf?sequence=1. Acesso em : abr. 2019.

GRAÇA, Hélio. Clima organizacional: uma abordagem vivencial. Brasília: FUNADESP, 1999.

Gomez,P.J.; Lorente,J.J.C.; Cabrera, R. V. Training practice sand organizational learning capability relationship sand implications.Journal of European Industrial Training, v. 28 , n. 4 , p. 234-256. 2004.

HO, W. H.; CHANG, C. S.; SHIH, Y. L.; LIANG, R. D. Effects of job rotation and role stress among nurses on job satisfaction and organizational commitment. 2009.

INFLUÊNCIA NA ROTAÇÃO DE TRABALHO. Disponível em: <http://www.scielo.mec.pt/scielo.php?script=sci_ arttext\&pid=S0874-02832015000200003> Acesso em : Fev. 2019.

JATURANONDA, C.; NANTHAVANIJ, C.; CHONGPHAISAL, P. A survey study on weight sof decision criteri a for job rotation in Thailand: Comparison bet ween public and private sectors. International Journal of Human Resource Management, v. 17, p. 1834-1851. 2006.

JUCIUS, Michael. Administração de Pessoal. São Paulo: Editora Saraiva, 1983.

LINDBECK, A.; SNOWER, D. J. Multitask learning and the reorganization of work: from Tayloristic to Holistic organization. Journal of Labor Economics, v.18, p. 353376. 2000.

MACÊDO, Ivanildo Izaias de. Aspectos comportamentais da gestão de pessoas / Ivanildo Izaias de
Macêdo,Denize Ferreira Rodrigues, Maria Elizabeth Pupe Johann, Neisa Maria Martins da Cunha. -9 ed. rev. e atual. - Rio de.Janeiro : Editora FGV, 2007.

MALINSKI, R. M. Job rotation in an academic library: damned if you do and damned if you don't. Lib. Trends, $v$. 50, n. 4, p. 673-680. 2002.

MARCONI, M. de A.; LAKATOS, E. M. Metodologia Científica. 5. ed. São Paulo: Atlas, 2010.

Técnicas de Pesquisa. 7. ed. São Paulo: Atlas, 2011.

MARRAS, J. A. Administração de Recursos Humanos: do operacional ao estratégico. São Paulo: Futura, 2002.

MURRELLS, T.; CLINTON, M.; ROBINSON, S. Job satisfaction in nursing: Validation of a new instrument for the UK. Journal of Nursing Management, v. 13, n. 4, p. 296-311. 2005.

OLIVEIRA, F. A.; DUARTE, R. N.; MONTEVECHI, J. A. B. O reflexo da mudança organizacional sobre o desempenho de uma empresa de autopeças: um estudo de caso. In: XXII Encontro Nacional de Engenharia de Produção, 2002, Curitiba. CD - room XXII ENEGEP, 2002.

OLORUNSULA, R. Job Rotation in academic libraries: the situation in Nigerian university library. Library Management, v. 21, n. 2, p. 94-98. 2000.

REICHEL, Harduin. Treinamento e Desenvolvimento. Curitiba: IESDE Brasil S.A., 2008.

ROTAÇÃO DOTRABALHO E CULTURA DA ORGANIZAÇÃO. Disponível em: http://www.administradores. com.br/artigos/marketing/rotacao-do-trabalho-e-cultura-da-organizacao/62676/. Acesso em : Jun. 2019.

SANTOS, J.C.S. Modalidades de Treinamentos. Qualidade Brasil. 2010. Disponível em: http://www.qualidadebrasil.com.br/artigo/administracao/modalidades_de_ treinamentos. Acesso em: 11 abr. 2019.

SILVA, M. A. C. da; ARAUJO, G. C.; VAZ, T. R. D. Gestão por Competências como Estratégia de Mudança Organizacional. In: XII SIMPóI 2009, São Paulo. 
SCHEIN, E. H. Coming to a New Awareness of Organizational Culture. Sloan Management Review, v. 25, n. 2, p. 3-16. 1984.

WILLIAMS, C.; CANTILLON, P.; COCHRANE, M. Pre-registration rotations into general practice: the concerns of pre-registration house officers and the views of hospital consultants. Med. Education, n. 349, p. 716-720. 2000.

ZIN, M.; MOHD SHAMSUDIN, F.; SUBRAMANIAM, $C$. Investing the influence of job rotation on career development among production workers in Japanese companies. International Journal of Business and Society, v. 14, n. 1, p. 135-148. 2013. 